\title{
4. The Irreverent Contemporary and Radical Tradition
}

\author{
Pat Hoffie
}

The Asia-Pacific Triennial of Contemporary Art (APT), an exhibition with an explicitly regional focus that presents art from Asia, the Pacific and Australia, is held at Queensland's QAGOMA. ${ }^{1}$ There have been seven iterations in its 20year history. This essay traces how the theme of the first triennial held at the Queensland Art Gallery (QAG) in 1993-Tradition and Change-sought from the outset to establish an interpretation of the 'contemporary' in the region as emerging from a series of critically responsive, historically and geographically specific discursive spaces. Drawing from an anthology of critical writing focused on the 20-year history of the APT in Broadsheet 41 (no. 4), the essay argues that this premise continued throughout the first three iterations of the exhibition, after which, as the parameters of the exhibition have grown wider, it moved towards a less critical, although more inclusive space. The essay examines the changing understandings of the terms 'tradition' and 'change' and poses questions about how a productive model for an 'irreverent contemporary' can be fostered within the region. The essay may therefore be positioned within current debates about what defines 'the contemporary' in art, particularly when viewed against non-Western contexts such as Asia. Ultimately, the essay argues that what is needed is a renewed attention to the particular conditions and contexts of art's differentiated production.

As Philippine historian, critic and curator Patrick Flores observed in his essay in Broadsheet, 'Revisiting Tradition and the Incommensurate Contemporary', ' the first APT established traditional practices as an important focus from which to observe, analyse and interpret the contemporary cultural production of the region. If this exhibition did not claim to undertake a 'world view' of contemporary art, then it certainly aimed to cover a fair slice of how it had unfolded in the region and, more importantly, it sought to challenge the

\footnotetext{
1 Editor's note: The Asia-Pacific Triennial of Contemporary Art is a series of exhibitions that have been held every three years since 1993 at the Queensland Art Gallery and also since 2006 at the Gallery of Modern Art in Brisbane, Australia (since 2006, the gallery's institutional spaces have been collectively labelled as QAGOMA). For a discussion of the project, see Part 1 of the Introduction by Caroline Turner, which explains that the purpose was to exhibit and collect contemporary art from Asia and the Pacific, including Polynesian and Melanesian Pacific art. The first APT concentrated on East Asia, South-East Asia and, to a small extent, the Pacific (New Zealand and Papua New Guinea), but the project now covers all of Asia (including, most recently, West Asia) and a wider selection of art from islands in the Pacific (http://www.qagoma.qld.gov.au/ exhibitions/apt).

2 Patrick Flores, 'Revisiting Tradition and the Incommensurate Contemporary', Broadsheet 41, no. 4 (December 2012): 234-39.
} 
fundamental assumptions of an uncritical contemporary that had grown as the fabled 'natural' inheritor of international modernism. The title of that exhibition-Tradition and Change-flagged this up-front, as if the very parameters for considering the art of the present time-what is inferred in the latter part of the APT's title as the 'contemporary' - might best be made through an assessment of the changes in and to traditional forms and practices. In this essay Flores returns to the understanding of the term 'contemporary' in a way that sets it apart from the assimilative all-inclusive term that is critiqued in other essays in the publication.

At that time of the first APT, contemporary expressions from the cultures of the region were largely unknown to Australian audiences. Indeed, this was equally true outside Australia: according to many APT observers, including many of the writers in the 2012 edition of Broadsheet, a broad knowledge of the diverse cultural practices of the region had not yet been established in the work of writers, curators, gallery directors and artists right across the region, let alone beyond it. Any knowledge that did exist had been garnered, generally speaking, through a vague sense of the artefactual production of the region via anthropological work collected in museums and/or through first-hand experiences of tourism.

As Flores points out, the publication that accompanied APTl was in part an invitation to consider the work of the region within, and in terms of, an imaginary space that might sit somewhere beyond the parameters of the 'globalised' international art realm that had been created by the impact of 'economic, technological and information changes'. ${ }^{3}$ Although, after 20 years, the possibility that any zone of 'beyond-ness' might exist seems barely credible, at that time, the option of an alternative reading to a homogenising sequential development of modernism into globalism still seemed possible from south of the equator, where glitches and blips in the history of modernism and postmodernism surfaced repeatedly in cultural expressions and histories that could not be easily accounted, translated and absorbed within mainstream historical accounts. For 'the south' harboured abundant evidence of modernism's failure to account for the wilful mistranslations that had produced a diversity of vital, critical and locally responsive cultural expressions engaging with colonisation and internationalisation in a range of ways.

A second important factor that rendered the possibility of the emergence of other understandings of 'the contemporary' lay in the fact that, by 1993 and even up to APT3 in 1999, the technological grip of ubiquitous personal computers and instant messaging had not yet taken hold across a great expanse of the globe. In the early 1990s it still seemed likely that not all zones of the earth's surface would

3 Caroline Turner, quoted in Flores, 'Revisiting Tradition', 235. 
be culturally as well as cartographically google-mapped. The third factor that underpinned the emergence of this (some might say naively) optimistic premise came about through QAG's awareness of the critical response of Indigenous Australians to historical accounts of cultural development in this country. The gallery's engagement with local Indigenous people in establishing cultural agency was focused on the contemporary during a critical project Mandjad or Balance 1991: Views, Visions, Influences. ${ }^{4}$ The aims, the process, the exhibition and the forum for this project prepared a fertile trough of scepticism about singular interpretations of, among other things, the development of modernism. This in turn produced fallow ground for the seeding of new possibilities for reassessing the development of non-Indigenous Australian art within the region.

None of the first three triennials, however, attempted to elaborate a definition of what that imaginary space might encompass. In fact, it could be argued that the early triennials conscientiously maintained an approach that avoided the limitations of theoretically predetermined parameters and definitions, in order instead to coax any interpretations that might emerge from interpretations of the work in the exhibitions, rather than being imposed by institutional or curatorial imperatives.

The curatorial overview for the first of the triennials created a discursive space within an imprecisely defined region where two impulses - that of tradition and of change - collided and morphed. Within this implied sphere, one bounded by indistinctly described geographies and imprecise and complex historical accounts, the concept of 'tradition' was, to a large extent, uncritically associated with memory, history and place. And it was also generally associated, by implication, with reflective expressions of an amorphous understanding of 'the past'. By default, the 'change' part of the dichotomy was associated with the here and the now - with the tempo of movement and the blur of shape-shifting. In the first exhibition-and in the two that followed-the contemporary production of artists was presented as having emerged from both aspects of these two contested areas: that of 'tradition' and that of 'change'. The 'contemporary' in the region, therefore, was presented and understood as having emerged as a result of this collision or chemistry.

This offered a purview that, although broad, was delineated in terms of significant differences from the art-historical assumptions that associated the term 'contemporary' with a category that absorbed modernism as an unproblematic and un-resisted inheritance. And, as such, this interpretation in turn signalled a shift in the understanding of the term 'contemporary' as it was understood within the many accounts of the post-postmodern/postcolonial world of 'international' art theory that was emerging from north of the equator.

4 Balance 1990: Views, Visions, Influences (Queensland Art Gallery, 1 March 1990). 
In these accounts the term 'contemporary' signified cooler shifts into newness; a term that was not tied to any of the messy, resistant (often wilfully resistant) ballast of the past. Even though Jean-Hubert Martin's controversial exhibition Magicienes de la terre, which was held at the Centre Pompidou and Parc de la Villette in 1989, proposed an interface between contemporary art and that produced by tribal 'Others', the underlying inference, according to a number of critics at the time, was that the exhibition foregrounded an understanding of 'traditional' with notions of 'primitive', spiritual and the past. Fredric Jameson criticised the way modernist impulses underscored the enterprise of the exhibition through a post-modern/post-colonial approach that conflated the art into a single, simplistic and non-contextually specific overview. ${ }^{5}$ Other critics described the exhibition as signalling a 'post-ethnic and post-historic' world order. Freed from the weight of having to consider the nuances implied by the myriad ways that understandings and interpretations of the 'modern' might have unfolded in particular regions, unleashed from the burden of having to consider the precise parameters of the 'colonial' in particular annexed territories, the term 'contemporary' offered a giddy limitlessness to possibilities for describing all work produced in all places as having emerged from a spaceless, ageless, noncontextually specific state of newness.

And this is the very point at which - from the inaugural exhibition in 1993 - the first of the three triennials made the potentially radical proposal by suggesting, in this region at least, the 'contemporary' had not emerged mysteriously as a weightless and shadowless ghost of the eternal now, but as a force that had developed through different forms in accordance with different circumstances and in relation to particular contexts. Rather, it was presented as an active, contested zone of conflict, contrapuntals, contradictions, productive confusions, contrarieties and contrasts. Wherever there was a fixed site, opinion, point of view, approach, idea, or assumed imaginary associated with the region, the first three APTs, and their associated forums, made room for an active engagement that teased, refuted or refused, augmented or opened up, fixed cultural assumptions about the development of modern art history and, alongside this, contemporary art.

As has been described for the first three iterations of the APT, for the general audience, the fact that the region was home to a range of disparate 'traditions' had already been established as an a priori, but non-specific 'given'; an expectation of generalised 'difference' held sway. This was also, in no small way, a drawcard to other players from the region. Quoting the response of Imelda Cajipe Endaya, an artist involved in APT1, Eileen Legaspi-Ramirez describes how the artists involved felt empowered in their role to effectively shape this nascent understanding:

5 Fredric Jameson, Postmodernism, or, the Cultural Logic of Late Capitalism (Durham, NC: Duke University Press, 1991). 
I felt rather privileged that my advice and comments were properly responded to and synthesised into the body of discussions and plans. ${ }^{6}$

And Iftikhar Dadi describes his experience of the APT as having taken place in a decade during which 'the idea of multiculturalism in contemporary art was just beginning to emerge as a significant issue globally' via a number of exhibitions. Among these, he says, the APT offered an important opportunity to map 'emergent currents in contemporary art'. He writes,

nevertheless, in its scale, criticality and its timing during the critical decade of the 1990's, the APT emerged as a key force formulating an understanding of the emerging practices in much of the Asian region. ${ }^{7}$

At that time, the role of giving form to a new understanding of the emerging contemporary practices in the region, and to tracing and describing the synergies and differences between them, was as much in the hands of the artists involved as it was in those of the curators, critics and writers.

Beyond the potential emergence of all such interpretations, however, the interpretive framework of the APT's curatorial position had already established an understanding that the cultural production it had selected from the region was avowedly 'contemporary'. Concomitantly, a great deal of the work selected and produced for the exhibition reflected the shared concerns, issues, subject matter and media of the 'contemporary', while simultaneously bearing traces of the 'traditions' from which it had emerged. That is, as with the exhibition itself, much of the work was expected to play a kind of double-dealing where at least two 'master' narratives were concurrently acknowledged. Alison Carroll, one of the curators of the first three APTs, recalls how the commitment to highlight the 'contemporary' made curators 'very cautious about choosing work that did not appear to relate to the contemporary world.' She remembers that curators were

cautious about choosing work that reinforced the audience's assumptions about Asian art being either unchangingly traditional or second-rate European. The emphasis was on work that was exciting, relevant, often personal, often political, visually strong and intellectually convincing, and if that was possible, it would carry the audience with it, which is indeed what did happen. ${ }^{8}$

Nevertheless, the first three triennials included evidence of the use of materials and themes that were 'indigenous' to their particular part of the region. For example, by 1993, the insistence on indigenous materials and themes in the work practice of a number of artists from the Philippines had, for at least a decade, been embraced as part of a resistance to the aesthetic and economic demands of

6 Eileen Legaspi-Ramirez, 'Largesse', Broadsheet 41, no. 4 (December 2012): 274-75, 275.

7 Iftikhar Dadi, 'Reflections on the First Decade', Broadsheet 41, no. 4 (December 2012): 266-69, 267.

8 Author's conversation with Alison Carroll (15 February 2013). 
an international art world dominated by Western values. To some, the first APT provided a kind of 'market place of ideas' through which they could flag their difference to broader audiences. Filipino artist Santiago Bose used this as the subject of his installation in APT1, for which he constructed a floor-based work that reflected the humble, makeshift, but nevertheless global, ambitions of a 'third world marketplace' within the more grandiose schemes and bravado of the international exhibition. In a much-quoted statement, the artist described what he believed to be central to the role of the artist in the region:

The artist cannot but be affected by his society. It is hard to ignore the pressing needs of the nation while making art that serves the nation's elite .... We struggled to change society, which is difficult and dangerous, and we also sought to preserve communal aspects of life .... The artist takes a stand through the practice of creating art. The artist articulates the Filipino subconscious so that we may be able to show a true picture of ourselves and our world. ${ }^{9}$

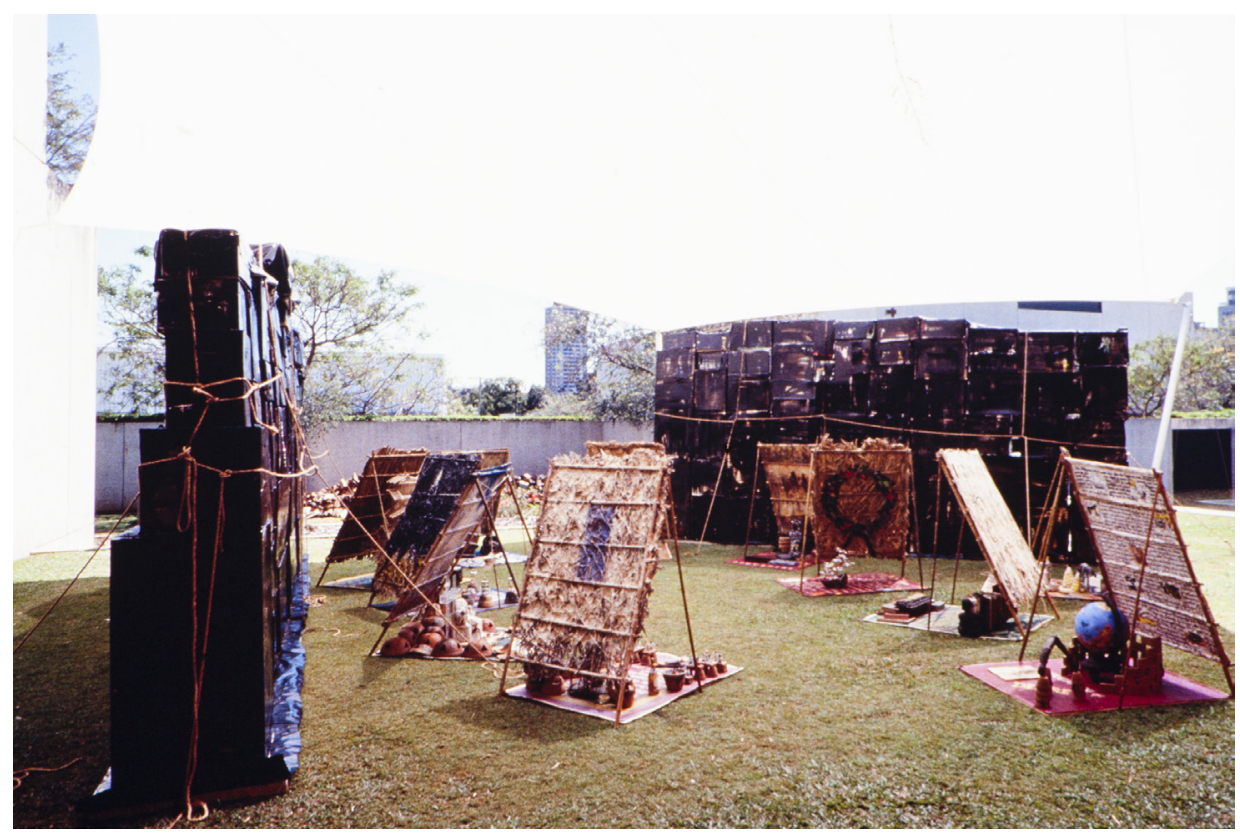

Santiago Bose, The Philippines, Talipapa (Marketplace) 1993 (exterior installation); installation comprising wooden boxes, organic materials, handcrafted and found objects; dimensions variable; installation view at the '1st Asia Pacific Triennial of Contemporary Art', Queensland Art Gallery, Brisbane, 1993.

(C) Estate of the artist; image courtesy: Queensland Art Gallery I Gallery of Modern Art (QAGOMA)

9 http://en.wikipedia.org/wiki/Santiago_Bose. 
A number of other artists produced work that incorporated aspects of 'indigeneity', 'nativism', 'traditions' in ways that were provocative and challenging, and that made it difficult to see where the boundaries between the category of 'tradition' and that of the 'contemporary' might lie. That year Roberto Villanueva, also from the Philippines, drew from indigenous ritualistic practices from the Cordillera region of northern Luzon for his performative installation Ego's Grave, for which he fired a clay pit in the outside courtyard of the water mall on the opening night. The water, smoke and fire were used to dramatic effect in a work that combined Cordillera cultural references with elements of Kabuki theatre and aspects of a Greek chorus. Audience involvement on the opening night metamorphosed into deeper and more significant personal concerns when the artist was diagnosed some days later as suffering from acute myeloblastic leukaemia. The artist's four-month stay in Brisbane, where he was hospitalised while he continued to fight the cancer, was marked by ongoing rituals of various kinds, including an Indigenous Australian smoking ceremony on the site of the installation. In the face of great concern and sadness, the principles of shamanism and Western medicine came together in ways that members of the local art community, who rallied in support of the artist, had not experienced before.

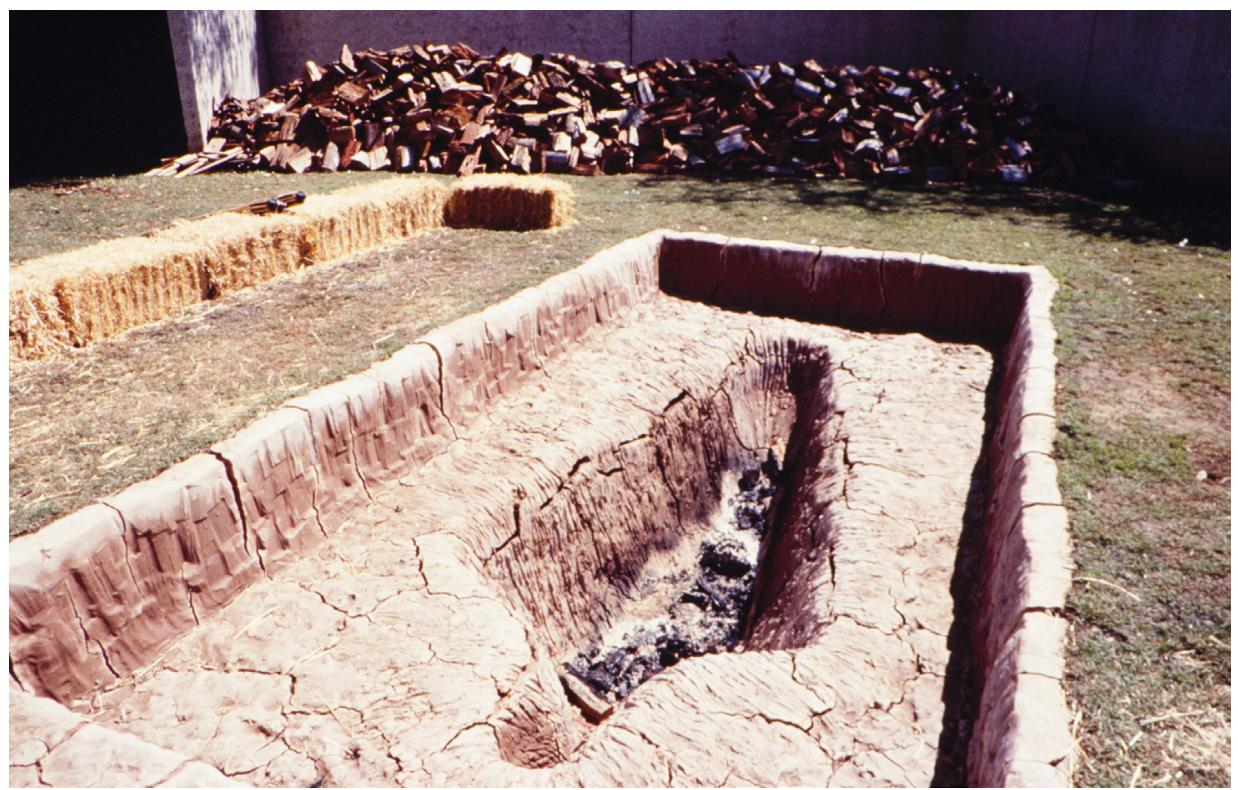

\section{Robert Villanueva, Ego's grave 1993; installation and associated performance; carved earth figure in outdoor pit; glazed terracotta; installation view at the '1st Asia Pacific Triennial of Contemporary Art', Queensland Art Gallery, Brisbane, September 1993.}

(C) Estate of the artist; image courtesy: Queensland Art Gallery I Gallery of Modern Art (QAGOMA) 


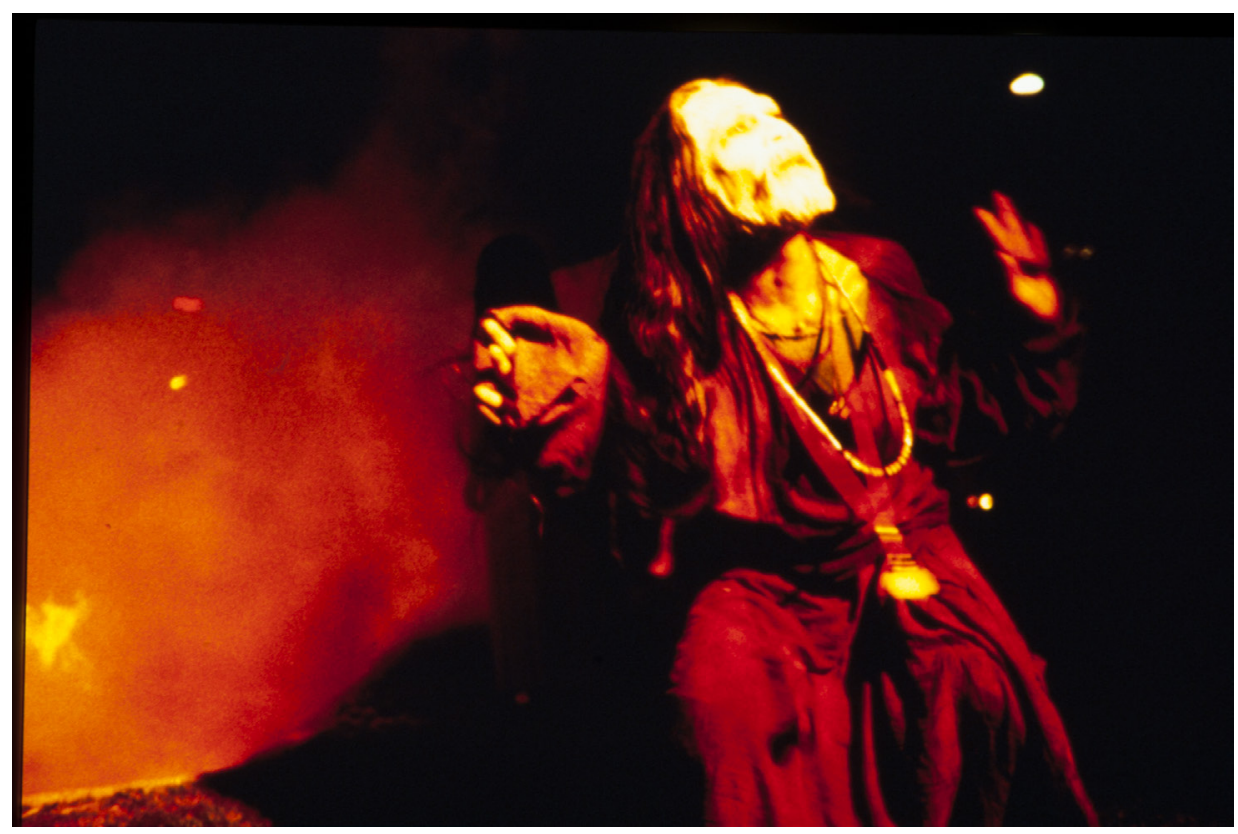

Roberto Villaneuva, The Philippines, performance in association with Ego's Grave 1993 at the '1st Asia Pacific Triennial of Contemporary Art', Queensland Art Gallery, Brisbane, 1993.

(C) Estate of the artist; photograph: Andrea Higgins; image courtesy: Queensland Art Gallery I Gallery of Modern Art (QAGOMA)

Other local responses to traditional expressions of marking and mourning that were included in the exhibition continued in personal and often moving ways the audience response to Indonesian artist Dadang Christanto's installation For those ... was evident on a daily basis through floral tributes, letters and notes to loved ones 'who had suffered'. The form of Christanto's bamboo and wood sculptures became appreciated as much for their capacity to act as a site for affective engagement as they were for their aesthetic strength, especially alongside the artist's related performance.

From the beginning, audiences were aware that there were surprises in store - the anticipated was not going to be delivered in terms set down by the institutions or the expectations of the West. But, perhaps surprisingly, local audiences were quick to embrace the differences offered in responsive and participatory ways. There was a preparedness to engage with 'Other' approaches and traditional practices, for audience members to respond in ways that were tentative but responsive and, at times, interactive. 


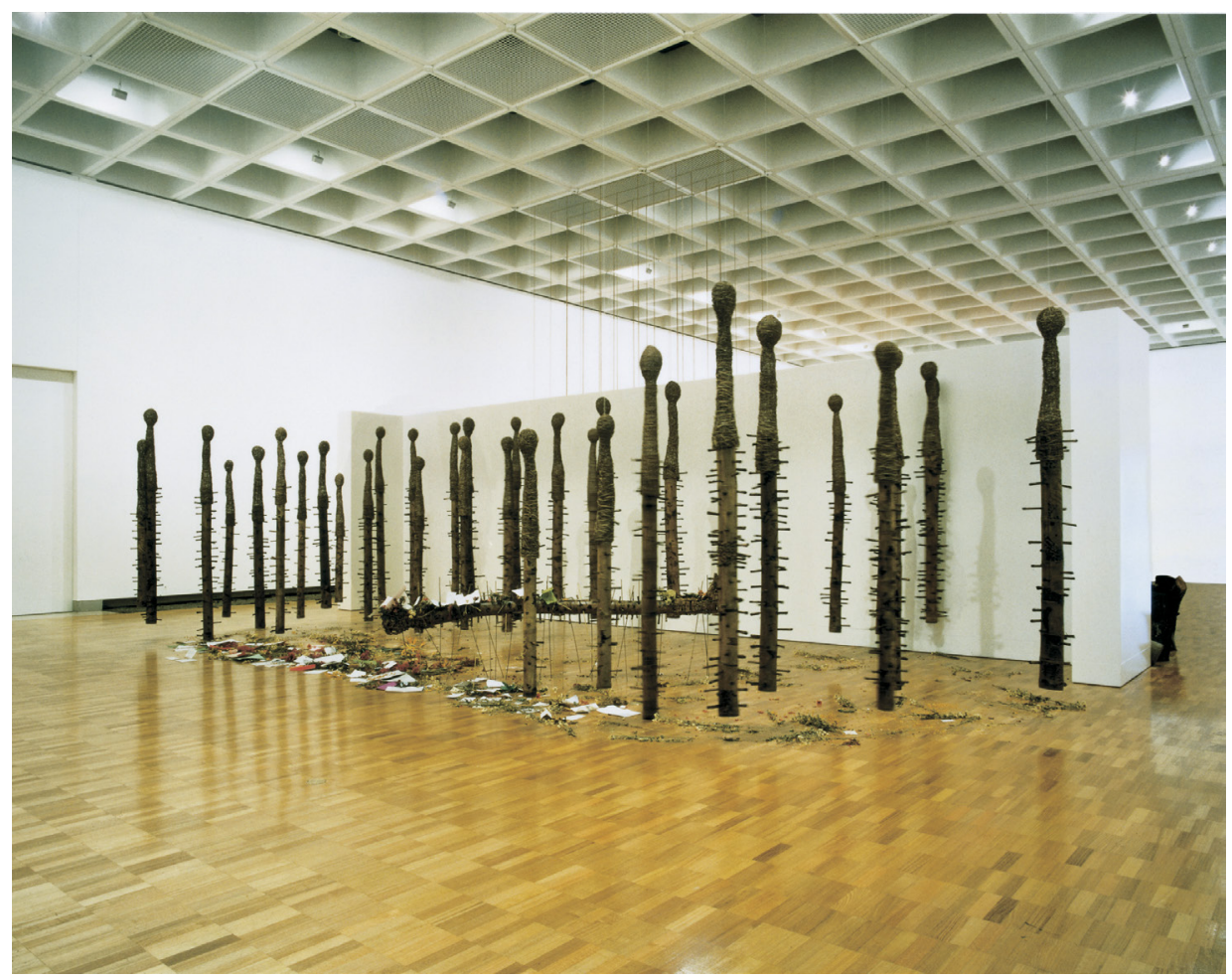

Dadang Christanto, Indonesia, b. 1957, For those who have been killed 1992; bamboo, metal; $110 \times 80 \times 335 \mathrm{~cm}$ (irreg., approx.); installed at the '1st Asia Pacific Triennial of Contemporary Art', Queensland Art Gallery, Brisbane, 1993.

The Kenneth and Yasuko Myer Collection of Contemporary Asian Art; purchased 1993 with funds from The Myer Foundation and Michael Sidney Myer through the Queensland Art Gallery Foundation; collection: Queensland Art Gallery; (C) Dadang Christanto; image courtesy: Queensland Art Gallery I Gallery of Modern Art (QAGOMA)

Twenty years on, in APT7, the installation at the entry to the Queensland Gallery of Modern Art (GOMA) suggested that there has been a radical change in what is considered to be 'contemporary'. Here, the architectural details of a Papua New Guinean spirit house or haus tambaran were part of the first artwork to greet visitors. And from there, down the high-ceilinged central hallway of GOMA, the featured works were predominantly those of the Kwoma, the Asmat ${ }^{10}$ and the Abelam people from Papua and New Guinea. Even so, the extent to which the inclusion of such works might be affected by, or affect, the notion

10 Editor's note. The Asmat people live in south-western New Guinea, an area that is part of Indonesia, along a river system flowing into the Arafura Sea. The Metropolitan Museum, New York, has a major Asmat collection, most of which was collected by Michael C. Rockefeller in 1961; see, http://www.metmuseum.org/ toah/hd/asma/hd_asma.htm. 
of 'contemporary' hovers in the exhibiting rooms like the proverbial elephant. Responses from some visitors from other countries noted that such work would be better included in exhibitions that were not featuring contemporary art. Other writers have claimed that, in terms of the comprehensive nature of the exhibition, the notion of 'contemporary' as an active, critical and contested site has lapsed into an all-inclusive lassitude.

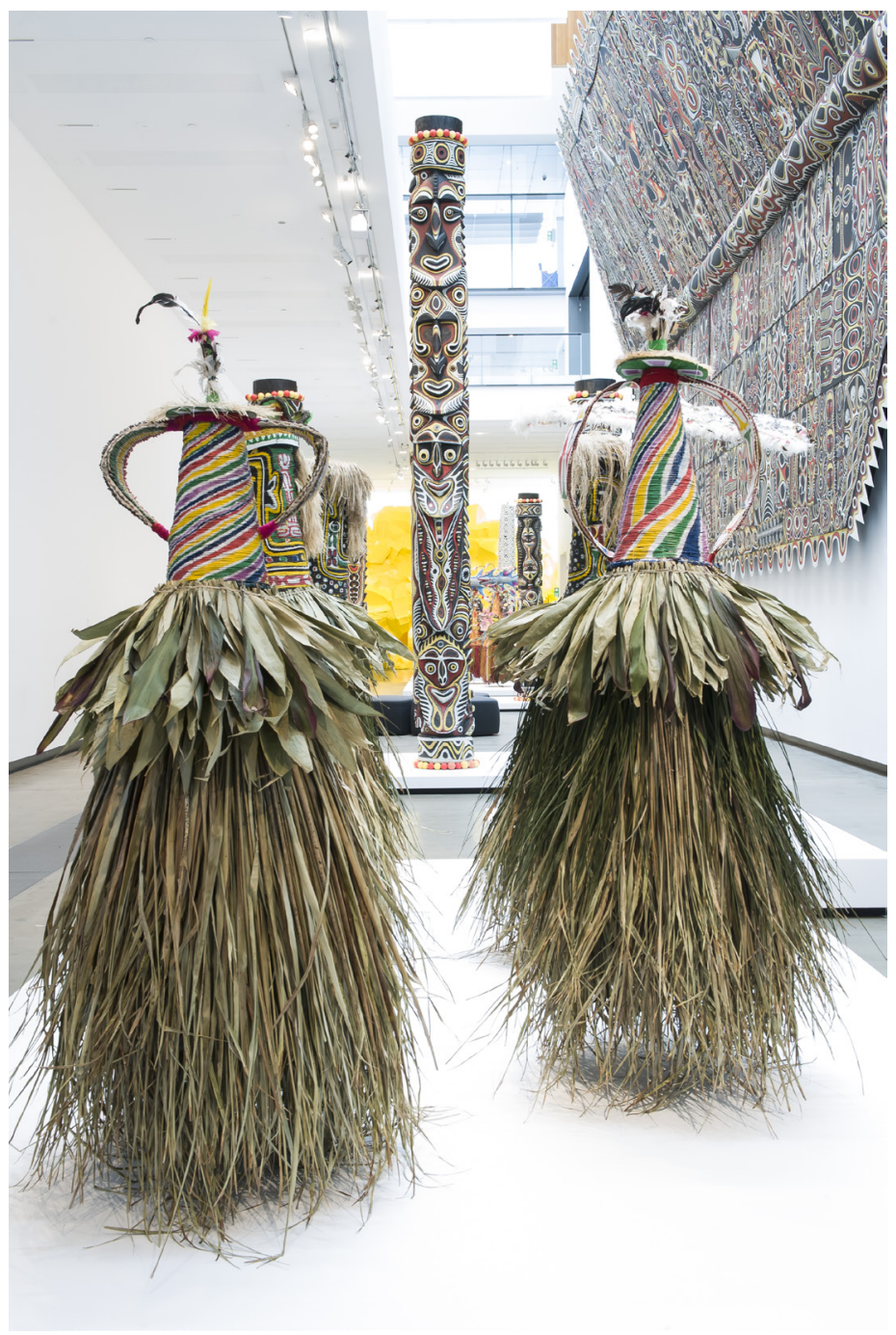

Kwoma Arts, Papua New Guinea, Koromb (Spirit House); installation view at the '7th Asia Pacific Triennial of Contemporary Art', Queensland Art Gallery | Gallery of Modern Art, Brisbane, 2012.

Purchased 2012; collection: Queensland Art Gallery; (C) the artists; photograph: Natasha Harth, QAGOMA; image courtesy: Queensland Art Gallery I Gallery of Modern Art (QAGOMA) 
According to some of these critics, the context of the current APT is evidence that the 'contemporary' is now fixed as a state of non-specific change- a place of incessant movement and change for the sake of change, leached of the potential for productive critical friction. Rex Butler describes his understanding of the contemporary as a yawning chasm of empty potential:

There is no positive centre from which the work comes, there is no tendency that is dominant, everything and everywhere is of equal interest and merit. And it is this that the exhibition must seek to capture: contemporary art's all-inclusiveness, scale, unclassifiability and incomprehensibility. The only principle, the only selection allowed is that which does not allow selection, that is contemporary in the sense of being post-stylistic, post-national and post-historical. ${ }^{11}$

According to this point of view, the productive contentiousness of the subject of the 'contemporary' - about what can or should not be included within its descriptors - has been exhausted, and what we are left with is a rule-less, contextfree, historically bereft vacuousness, not unlike the flat pristine wasteland of a wealthy man's cultural trophy room.

Some artists in the exhibition, however, used this as the subject matter of their work: Graham Fletcher's Lounge Room Tribalism series offers a brilliant and pithy critical reflection on the museum's role as an ersatz cultural trophy room, one that presents indigenous art as a decorative addendum to the ongoing project of modernism. Fletcher's moderately sized canvases stand out as almost anachronistically modest in scale, execution and subject matter, presented as they are within the belly of an exhibition that has increasingly tended to feature the grand statement. Within this context, the paintings make a humble salute to the modest power of silence and simplicity. Yet, something about the subject matter of the work, and the way in which the pieces resonate with and within the broader context of the exhibition, offer pertinent insight into the ongoing role of international modernism and the appropriation of the indigenous and the traditional.

Fletcher's series features scenes from domestic interiors from the 1950s and 1960s - around the time, according to the artist, when there was 'a point of intersection of Western and non-Western cultures within the homes of many collectors and consumers' ${ }^{12}$ With skeins of paint that seem to have been effortlessly applied, the works make more than a cursory nod to a DIY clunkiness. This in turn evokes a light, deceptively throwaway spirit in works that are pregnant with criticality. The initial response to these images is that

11 Rex Butler, 'All or Anything at All', Broadsheet 41, no. 4 (December 2012): 277-79, 279.

12 Graham Fletcher, interviewed by Ruth McDougall (July 2012) in The 7th Asia-Pacific Triennial of

Contemporary Art (Queensland Art Gallery/Gallery of Modern Art), 114. 
we are witnessing the origins of an all-too-familiar obsession with the details of lifestyle and 'good living' that are the nascent ancestors of our contemporary IKEA internationalism. As Ella Mudie has pointed out, ${ }^{13}$ however, Fletcher's interiors belie the 'inherent instability of the domestic'. Poised amidst the 'form follows function' design style of the objects in the room, the artefacts and items of indigenous cultural production are mutely brooding inclusions. Fletcher is well aware of the contradictions of his own position - as a New Zealand artist of Samoan and European ancestry, his fascination with the Oceanic collection of Surrealist Andre Breton is one fraught with productive incongruities. He writes of the tribal artefacts featured in his Lounge Room Tribalism images:

For me these objects no longer emanate the power of the Old World, but are historically aestheticised as objects of the New, thereby raising questions of context, assimilation, ownership and authenticity. In a broader sense, what I try to suggest is the complex relationship between Western and non-Western cultures and how many indigenous artists today are subject to influence and transformation in the advent of globalisation. ${ }^{14}$

As sites of tension where items of 'the incorporated indigenous' quiver and quake with indignant potency, Fletcher's work is a microcosm of the exhibition in which they are included. It carefully poses the rifts, fissures and frictions of inclusion of traditional forms of cultural production as positive problems worthy of further reflection and enquiry. The mute, bland and impassive artefacts of modernity that inhabit the empty rooms of Fletcher's imaginary world become implicitly destabilised by the silent challenges of traditional artefacts.

Within the larger, all-inclusive zone of the contemporary exhibition, a benign inclusiveness is at play; one that admits all, but which simultaneously gives alltoo-scant attention to the details of context. This is not dissimilar to the bland inclusiveness of Fletcher's 'contemporary modernist' interiors. It is an easy jump to see Fletcher's world as having re-emerged in the post-postmodernist modernism of APT7.

Instead of including traditional work as primitive inclusions, however, a generalised acknowledgement of the contemporaneity of this work is evident throughout the didactic panels included in the exhibition, and in the exhibition catalogue. This is illustrated in curator Ruth McDougall's description of the Asmat work,

the bisj poles, wuraman and spirit masks on display themselves derive from cross-cultural encounters. Most of these works were created

13 Ella Mudie, 'Graham Fletcher's Lounge Room Tribalism', Art and Australia 50, no. 2 (Summer 2012).

14 Fletcher, The 7th Asia-Pacific Triennial of Contemporary Art. 
specifically as art works for sale; in the Asmat region, the appreciation and acquisition of carving and weaving have taken place since the first collectors visited the region in the early twentieth century. ${ }^{15}$

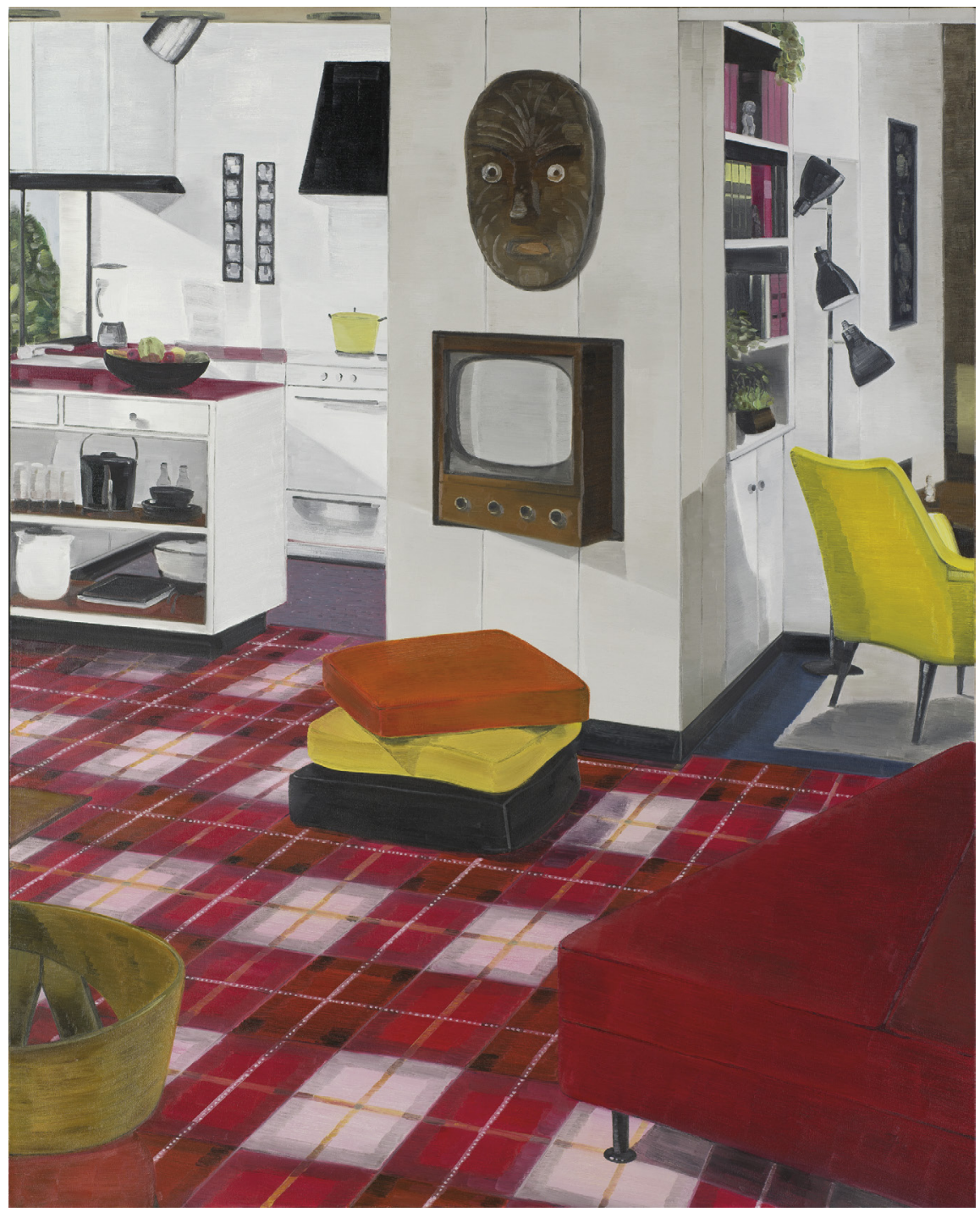

Graham Fletcher, New Zealand, b. 1969, Untitled (from Lounge Room Tribalism series) 2010; oil on canvas; 162 x $130 \mathrm{~cm}$.

Acc. 2010.632; purchased 2010 with funds from the Estate of Lawrence F King in memory of the late Mr and Mrs SW King through the Queensland Art Gallery Foundation; image courtesy Queensland Art Gallery | Gallery of Modern Art (QAGOMA)

15 McDougall, 'Asmat; The Eloquence of Wood', in The 7th Asia-Pacific Triennial of Contemporary Art, 89 
Even so, more comprehensive and detailed descriptions of the way in which these works have come to be understood as 'contemporary' would have affected a deeper understanding of them, their content, the artists and their relationship to their own community and the potential relationship of that community to the viewing community. The presence of rich histories of confrontation and negotiation with the various aspects of modernity are only hinted at:

Over the past 50 years, with the introduction of Christianity, the development of cash economies and increased cultural diversity, there has been an influx of new ideas, materials and values. This has had a considerable influence on how the Asmat view their work. ${ }^{16}$

This kind of generalised description of the inevitable processes of modernism somehow suggests that the details of how the work and the artists 'got here' is not as important as their inclusion; as if their entry into an exhibition of contemporary art can be paid for by a no-questions-asked-no-answers-given ticket. New Zealand writer Peter Brunt draws attention to this anomaly of Western international exhibition practice:

We members of the 'art cult' know next to nothing about the art history of the Kwoma - or that of the Asmat, the latmul, the Abelam or any of the other tribes from Papua New Guinea and the Indonesian province of Papua, who are making a splash at APT7. It is not that they don't have one; the art they have made for the exhibition bears complex histories in which it has had to negotiate its survival and transformation in relation to the impacts of missionaries, colonial administrators, collectors, national bureaucracies, the tribal art market and more. Those histories can be framed as projects of colonial resistance, cultural survival, empire and decolonisation, modernism and nationhood, religion and secularisation, the global diaspora of material culture and cultural memory, tribalism and the global art world - the list goes on. But those are stories barely told or understood in the consciousness of the contemporary art world. ${ }^{17}$

And, in another statement, Brunt describes the extent to which this stands in contrast to those late-admissions to recognition as art of the international contemporary' who have long been aware of the shapes and parameters of a range of Western cultural structures and the expectations that go with them:

There is no tribal artist in New Guinea or its surrounding archipelegos who has not pondered his or her relationship to either the 'State'

16 Ibid.

17 Peter Brunt, 'Transcultural Space and Art Historical Consciousness', in The 7th Asia-Pacific Triennial of Contemporary Art, 72-75, 72. 
(Indonesia, Papua New Guinea, Australia, Germany, the Netherlands, Britain), Christianity, anthropologists, the tribal art market, the museum world, expatriate kin, urban relatives or the past or future.$^{18}$

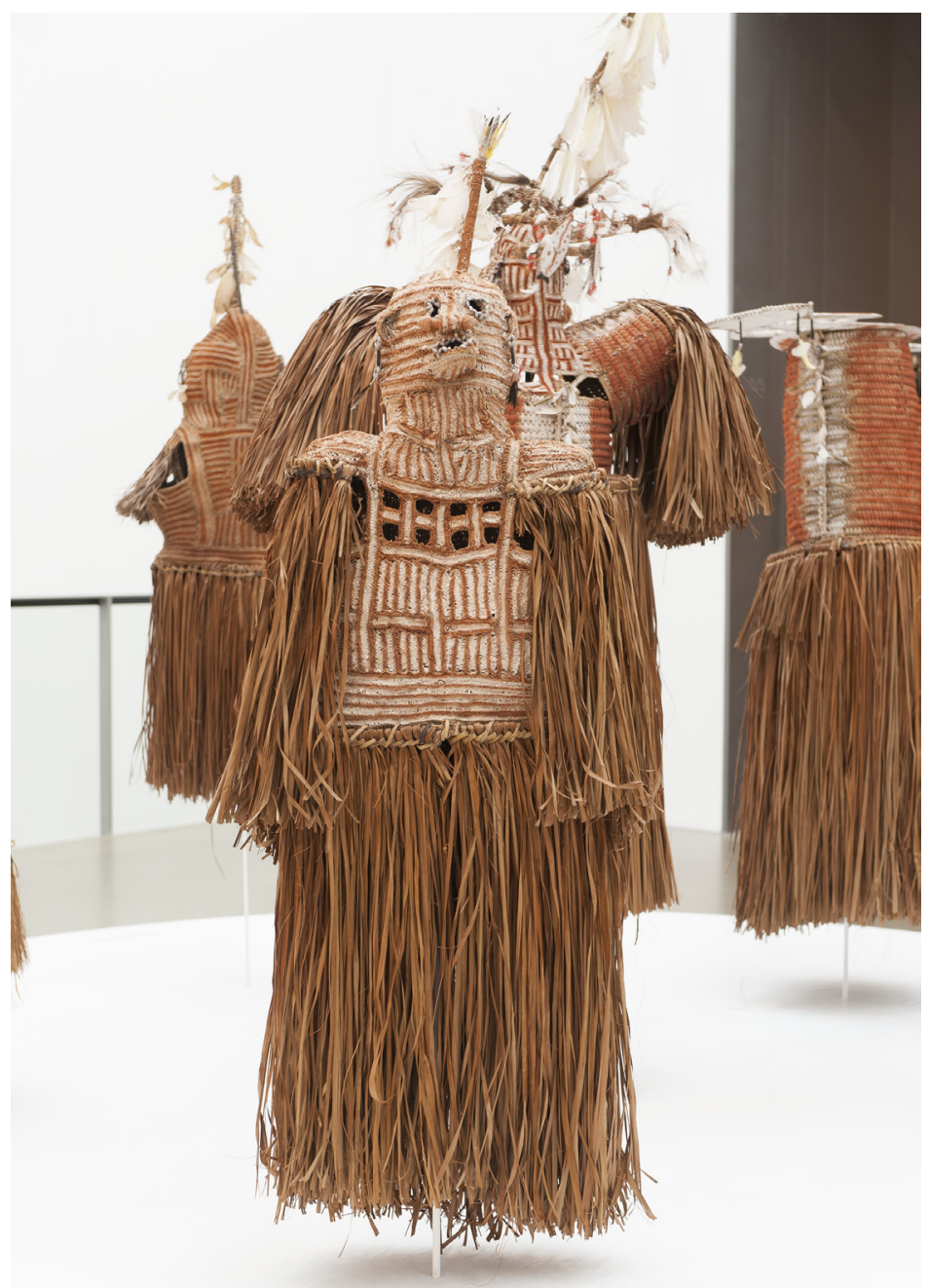

Installation view of Asmat artists, Yakobus Serambi, Primus Isimin and Amatus Ahmak, Bi jumbo, Manimar and Doreo (Spirit masks) 2012; '7th Asia Pacific Triennial of Contemporary Art', Queensland Art Gallery | Gallery of Modern Art, Brisbane, 2012.

Purchased 2012; collection: Queensland Art Gallery; (C) the artists; photograph: Mark Sherwood, QAGOMA; image courtesy: Queensland Art Gallery I Gallery of Modern Art (QAGOMA)

18 Ibid 
For those authorities - historians, critics, curators, writers - who might assume knowledge of the 'international art world', this is startling stuff. Brunt's statement makes it clear that, for a significant period of time, these 'tribal artists' have been in possession of an historical depth of knowledge and an understanding of cultural complexity that is not evident in the presentation of overviews of 'international contemporary art'. As Brunt says, the legacy of our 'knowing too much' about Western art stands in the way of our capacity to engage with a range of others in our region, who may have a different world view, or who - perhaps surprisingly - might seek to 'not fit ' within the flawed monologue of global modernism that has pre-assigned them a particular role. That single-voice narrative has stood in the way of what might have been a more polyfluent interpretation of the emergence of the 'contemporary' in the region, obscuring the specific contexts in which contemporary art develops outside of the West.

The kind of awkwardness and, at times, shambolic ruptures that characterised the presentation and language of the first three APTs, as artists, critics and writers stumbled in search for the words and forms to describe the synergies and continuities they were witnessing around them, has been supplanted by the glitch-free, blooper-reduced purity of an international, globalised account of the 'contemporary'. According to some critics, the burgeoning growth of international biennales throughout the first decade of this century represented a steady move towards the 'contextless contemporary'. Although APT4 made an attempt to reconnect regional tendencies with those of the senior artists of the region who had gained international recognition, by APT6 the critical potential of the exhibition to follow through with its original premise to rethink the contemporary had lapsed. Andrew Maerkle writes,

In this sense I have to admit that when I finally made it to see the Triennial, the most disorienting aspect of APT6 was not any juxtaposition of 'traditional' with 'contemporary', but rather the juxtaposition between the 'contemporary' and the 'contemporary'. ${ }^{19}$

The extent of the ground lost, and the degree to which this kind of enervated, reductive account is at odds with the region's history of critically engaged confrontations, contextualisations, appropriations and renegotiations of the international influences of Western modernism throughout the twentieth century is apparent within even the most cursory historical point of view. Here, Maerkle's synopsis reminds us that, throughout the previous century, the art of the region continuously developed in a spirit of informed critical responsiveness between the 'traditional' and the 'change' resulting from external influences:

19 Andrew Maerkle, 'Lable/Babel', Broadsheet 41, no. 4 (December 2012): 251-52, 252. 
Entering the twentieth century, artists returned from study in Europe with experience in movements from Cubism and Futurism to Dada and Surrealism, upon which they elaborated and shared with their peers, creating an avant-garde that operated in distinction to the 'traditional' and the conventionally 'Western'. ${ }^{20}$

What, if anything, has been lost in this quick transition to everything being contemporary? Not all critics lament the passing of the more definitive categories of cultural definition. Ranjit Hoskote writes,

We have put behind us the essentialist, static characteristics of people, regions, cultural practices and artistic production on the basis of such entities as 'civilisations', 'traditions', 'blocs', and 'identities'. Instead, we attend to the dynamics of the intensely networked, migratory, layered global present. We grapple with it, in the atlas-resistant, lexicon-eluding fullness of its unexpected adjacencies and interstitial hybridities; we probe its unsought intimacies and unexpected estrangements: its circulatory paths along which economic migrants, proscribed refugees, technocratic itinerants and cultural pilgrims travel; and the continuous renegotiations between people and places, between interpretation and location, between position and predicament, between citizenship and alienation, that it demands. ${ }^{21}$

But Hoskote's exhortation to drop categories such as 'civilisations', 'traditions', 'blocs', and 'identities' does not, ipso facto, vouch for the adoption of an homogenised account of the contemporary; rather, it demands an energetic enquiry that searches and re-searches the global present, not as a thing that is presumed, assumed, expected to be an immediately recognisable hereditary entity. Hoskote calls for attention to the 'unexpected adjacencies'; he invites unwavering discrimination in responding to the subtleties of place ('location'), 'position and predicament', context and purpose: it is doubtful that the 'lexicon-eluding fullness' that Hoskote alludes to could be crammed into any pre-packaged understanding of a de-limited 'contemporary.'

But, it is not the intention of this argument to lay the blame for any lapse in the critical potential of the 'contemporary' on the shoulders of the APTs alone; as Hoskote argues, since the first three APTs, there has been a major strategic shift in international survey exhibitions that has moved the discursive parameters for presenting and considering the work from the 'intercultural' to the 'transcultural', rendering approaches that emphasise identity through markers such as nation-states outmoded. In his critical response to this

\footnotetext{
20 Ibid.

21 Ranjit Hoskote, 'Wager on Cosmopolitanism. On the 7th Asia-Pacific Triennial', Broadsheet 41, no. 4 (December 2012): 258-60, 258.
} 
trend, he calls for curatorial approaches that move away from the impulses of 'representation' (of cultures, nations and regions) to those of 'translation', and draws upon curator Kathryn Weir's words to describe ways of thinking 'in terms of changing, generative relationships rather than established identities. ${ }^{22}$ Although respectful curatorial humility in the face of identity-interpretation is always essential in zones of either cross-cultural and inter-cultural (if not trans-cultural) endeavours, there may, however, be a case for arguing that any jettisoning of understandings of geo-cultural histories of the region, at this stage, is pre-emptory. The presentation of the work of the Kwoma, Asmat and Abelam is a case in point; the lack of a deeper historical and cultural understanding of the development of their 'traditional' forms, as they have been confronted by the successive changes to their context and understanding of the world, prevent audiences from acquiring a comprehensive, nuanced appreciation of the work that is currently being celebrated as a 'contemporary' manifestation of past traditions.

The term 'tradition' is itself fraught; but, it is fraught in exciting, potentially radical ways. In his essay in Broadsheet, Flores problematises the term 'tradition', analysing it through three vectors: its association with (1) 'civilisation'; (2) 'folklore'; and, (3) 'culture'. This analysis explores the parameters of the term, and reconsiders the extent to which 'interpretation' might be utilised as a term with continuing validity in considering, understanding and interpreting the development of artwork in the region. He writes,

It is through the meditations of Roces on the term 'culture' that we are able to revaluate the consequences of the theory of tradition and co-extensively of the constantly re-negotiated and re-appropriated neo-traditional and the neo-ethnic, a subject that deserves separate discussion .... To a significant extent, this revisit to tradition gives us the opportunity to reconsider a theory of transculturality or equivalence, or the exasperating problematic of a contemporary 'cross culturality' ${ }^{23}$

Flores shares Weir and Hoskote's conviction that the 'local' has an 'ever elusive address' and, again like Weir and Hoskote, he advocates 'an ethical responsibility' towards remaining wary of the folklores of nationalisms and identity. Flores goes one step further, however, when he advocates an understanding of the traditional as a 'critical inheritance' that is 'always present'; and, in turn, he steps away from the position shared by Weir and Hoskote when he warns against any collapse into a transculturality or cross-culturality that might become bland equivalence. Furthermore, Flores warns about the way the demand for 'contemporary equivalence' fosters a particular predicament for artists working

22 Kathryn Weir quoted in Hoskote, 'Wager on Cosmopolitanism', 259.

23 Flores, 'Revisiting Tradition', 239. 
in a postcolonial context, who are faced with the double bind of experiencing 'a latecoming both to their own traditions and to the foreign one' ${ }^{24}$ Lost in limbo, caught between a diminished sense of tradition and a contextless contemporary, their art seems doomed to resonate hollowly only within the brittle veneer walls of 'the new'.

In his interview for the APT7 catalogue, Fletcher describes a passage from Robert Louis Stevenson's novella The Beach of Falesa (1892) in which a colonial trader sets up a 'haunted cave' filled with wondrous items from both Western and non-Western sources in an attempt to awe and control the indigenous people. Fletcher speaks of his own images of modernist interiors, haunted by the presence of indigenous artefacts or cultural productions, as the inheritors of that magical cave. The 'pleasure domes' of contemporary art spaces are effortlessly interpretable as the offspring of such colonial appropriation and control. Fletcher's metaphor and the images he produces open the way towards a less authoritarian, more open and playful analysis of the emergence of the contemporary. If there is a haunting at hand, then surely part of that lingering melancholy has to do with the failure of negotiation, with misinterpretations, with the sheer stupidity of not taking time to listen, look and think about the differences that contextually responsive traditions have worked with over time. The 'indigenous objects' in Fletcher's otherwise ethnically cleansed interiors glower and thrum with the indignity of having been included in a space to which they never requested entry. We look at these images and we are simultaneously caught in the potential of understanding what those objects might tell us, if only they could speak, and of also considering how their presence threatens to shatter the ordered elegance of the modernist design chic. As viewers, we are left almost willing that to happen.

And what if it did? What if the rooms were blasted apart with the intensity of that built-up tension? What if all the bits and pieces had to be reconfigured? What if we had to stop and slowly, carefully, start asking questions about pasts and places, allegiances and alliances, and enmities before we put it together again in another (temporary) iteration? Who would we ask to help us do it so that it didn't happen again? What might the real costs of that consultation be? How much time might that take? What if it looked a little messy? What if it didn't look like the all those catalogues of beautiful rooms before it?

Natasha Conland's term, the 'irreverent contemporary' may be adequate to the task of encompassing that possibility:

The irreverent contemporary might however embrace the possibility of failed dialectics, disagreement, a less majestic turn of phrase and 
conflict might be there at least as a possibility. In the first three APTs the symposia were widely felt to own this position, but in the absence of a more sustained formal dialogue, how does an exhibition hold this state while assuredly celebrating and owning its outcome to provide the world a location for viewing art of the Asia Pacific ${ }^{25}$

The APT's specific regional distinction among biennales/triennales of the world, namely its mission to address the geo-cultural specificity of the AsiaPacific, is clearly indicated in its title. It is therefore uniquely placed, as it has always been, to lead and advance the critical frames and debates on the contemporary as a necessarily context specific project. One of the hopes of the first three APTs was that the region might be able to offer an understanding of the emergence of the contemporary in a way that was not as conclusive as that presented in exhibitions north of the equator; in a way that sought for a gradual, slow, collaborative and consultative understanding that made way for disagreements and 'failed dialectics'. Not all of that potential might yet be lost: the APT's unique structure offers both the pedagogy of a growing archive and a growing collection, offering both a major recurring exhibition and the steadily amassing research of a museum, prepares the ground for the possibility that an 'irreverent contemporary', based on an acknowledgement of the fundamentally radical nature of many traditions in the region, might still be recognised and articulated.

25 Natasha Conland, 'I Fell in the Pacific Rim. I Fall in the Pacific Rim. I Will Be in the Pacific Rim', Broadsheet 41, no. 4 (December 2012): 262-63, 263. 
This text taken from Contemporary Asian Art and Exhibitions: Connectivities and world-making, by Michelle Antoinette and Caroline Turner, published 2014 by ANU Press, The Australian National University, Canberra, Australia. 